\title{
A CASE OF PARTIAL CONGENITAL HEMI-HYPERTROPHY
}

\author{
BY
}

\section{A. HUSE}

From Dudley Road Hospital, Birmingham

(ReCEIVED 23RD February, 1944)

HEMI-HYPERTROPHY, or abnormal enlargement of one side of the body, is of interest because of its varied forms and its frequent association with other congenital abnormalities, including mental deficiency. Wagner reported a case in 1839 , and in the ensuing century about a hundred cases of partial or complete hemi-hypertrophy have been recorded.

A brief description of the following case of hemihypertrophy, associated with Von Recklinghausen's disease, will serve as a basis for discussion.

Case report.-A male, L. G., aged 39 years, was admitted as a feebleminded patient to Leavesden Hospital in 1931. He was the second of three children of whom the others died of tuberculosis in their first year. As a child he had measles and whooping cough. He began to talk and walk at $2 \frac{1}{2}$ years. At 8 years he fractured his right clavicle and he says that it was after this that the difference in size of his two arms became noticeable. He attended a primary school for four years, became tuberculous and was admitted to a special school for mental defectives in 1903.

Both parents are dead and no history of the family is available.

The patient is a feeble-minded adult, with a mental age of $65 / 12$ years by Burt's revision of the Binet-Simon scale. With performance tests (Drever and Collins) he has a mental age of 8 years. He is well behaved, and a good ward worker, and makes woollen rugs in his spare time.

Physical examination.-Height $4 \mathrm{ft}$. 9 in. Weight $7 \mathrm{st} .9 \mathrm{lb}$. Although short in stature, he is disproportionately broad, with a "Punchinello" type of thorax. There is marked difference in the length and girth of the arms, and, in a lesser degree, of the legs. The disproportion is indicated in the following table:-

\begin{tabular}{|c|c|c|c|c|}
\hline $\mathrm{Arr}$ & $\begin{array}{l}\text { RIC } \\
66.5\end{array}$ & & $\begin{array}{l}\text { LEFT } \\
70.5 \mathrm{cn}\end{array}$ & $\begin{array}{l}\mathrm{T} \\
\mathrm{cn}\end{array}$ \\
\hline arm, girth . & 23 &, & & \\
\hline arm, length . & .. 40 & ," & $42 \cdot 5$, & \\
\hline & .. 23 & ," & 25 & \\
\hline finger, length & 10 & , & $10 \cdot 7$, & , \\
\hline irth & $19 \cdot 5$ & , & 21 & , \\
\hline & $77 \cdot 5$ & , & $78 \cdot 5$, & \\
\hline h & .. 42 & ," & 43 & \\
\hline jot, length & .. 21.5 & ", & 22 & , \\
\hline ynamometer, hand & .. 100 & & 80 & \\
\hline
\end{tabular}

The difference between the upper arms is very noticeable (Fig. 1). The left shoulder and scapular region are larger in all dimensions than the right, and this difference is seen in both osseous and muscular tissues. The deltoid, trapezius and pectoralis major muscles stand out, and the enlarged muscles are firm to the touch, but, in spite of their appearances, when tested with the dynamometer and by movements against resistance, it can readily be demonstrated that they are actually weaker than those on the normal right side.

When the patient stands erect, the left shoulder is on a higher plane than the right. There is no limitation of movement in the joints of the four limbs. There is, however, considerable limitation of movement in the cervical spine in all directions; lateral movement is slight and extension of the neck is so limited that in the supine position the occiput remains at a height of several inches from the floor. When the patient is asked to direct his gaze to the ceiling, upward movement of the eyes is not accompanied by any extension of the head (see Fig. 1).

There is marked mid-dorsal kyphosis. The thorax shows a depression below the manubrium sterni, and respiratory movements of the chest wall are small.

Chest examination shows the following abnormal findings: poor movement, dullness to percussion at both apices, and poor air entry throughout. X-ray shows fibro-caseous tuberculosis at both apices. Temperature and pulse are normal, his weight is steady and he has no cough or sputum. The heart and abdomen reveal no abnormal findings. Blood-pressure is $105 / 65$. The cranial nerves are normal, except that both pupils are small and eccentric, and react sluggishly to light and on accommodation, and that the cornea of the right eye shows an old traumatic central opacity.

The left arm, though larger, is weaker than the right; no difference in motor power can be detected in the legs. Sensation is normal throughout. The tendon jerks are all brisk and equal, the abdominal reflexes absent, the plantars flexor. Sexual development is less than normal, but the testes are of equal size. On the trunk there are two large and several small cafe-au-lait areas of pigmentation. On the left forearm there was one subcutaneous nodule, which was removed for microscopic examination. This proved to have the relatively cellular structure of a soft fibroma.

\section{Biochemical investigation}

Blood Wassermann, Negative.

Serum calcium

$=1.9 \mathrm{mgm}$. per cent. Serum phosphatase $\quad=4.5$ units.

\section{Radiological examination}

1. The skull is symmetrical in its two halves and the bones of the vault are of equal density and thickness on the two sides. There is no indication of acoustic or other neurofibromatous tumours.

2 . The vertebral column shows marked kyphosis and osteoporosis, and the intervertebral disc spaces are diminished. There is calcification of the anterior vertebral and interspinous ligaments.

3. The humerus and hand. The left humerus, the radius and ulna, and the bones of the left hand are shown to be definitely larger than the right (Fig. 2). 


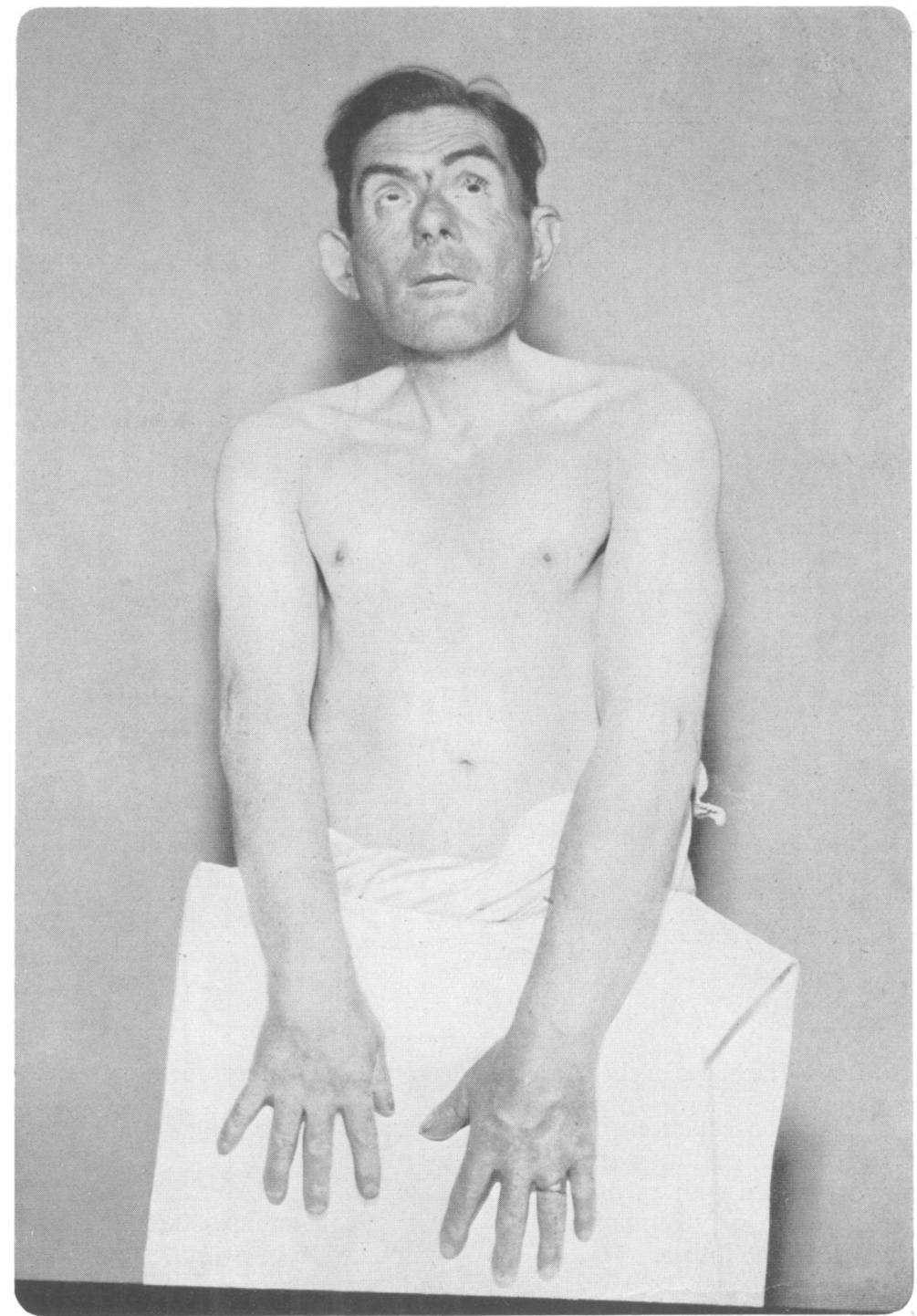

FIG. 1.-Note enlargement of left upper limb, limb girdle. There is marked prominence of the left pectoral and deltoid muscels. Patient is endeavouring to look upwards.

\section{Discussion}

The asymmetry in this patient cannot be due to muscular atrophy of the limbs of the right side of the body such as that found in mild forms of infantile cerebral hemiplegia, for in this case the muscles

- show no evidence of wasting and although smaller than those of the left side are definitely more powerful. . Furthermore, there is entire absence of signs of neurological involvement of the cortico-spinal motor path. Likewise the preservation of normal cutaneous and deep sensibility excludes the possibility that the case has a syringomyelic origin similar to that reported by Guillain et al. (1925). Again, in pseudohypertrophic muscular dystrophy, the hypertrophy is bilateral, hypertrophy is most evident in the legs and the affected limbs do not show enlargement of the bones. In the very rare disease dystrophia musculorum hyperplastica, there may be rarefaction of bone, but never enlargement.

In the case now reported, the enlargement on the affected side involves both osseous and muscular tissues, and has points of resemblance with cases reported to be congenital in origin. In those which have come to autopsy (Gesell, 1921), it has been found that the increase in muscle bulk is due to an overgrowth of connective tissue.

The presence on the patient of several cafe-au-lait patches, a single subcutaneous fibroma, and the associated kyphoscoliosis with calcification of the anterior vertebral ligament and interspinous ligaments are consistent with the view that this is a case of von Recklinghausen's neurofibromatosis, a disease in which disturbances of growth are known to occur. Whether the associated mental defect is 




FIG. 2.-The bones of the left hand are larger than those of the right hand.

merely fortuitous, or is a consequence either of a diffuse cerebral sclerosis which occurs in some cases of hemi-hypertrophy associated with mental defect, or of a cerebral gliosis which may occur in neurofibromatosis, must be left to the future.

\section{Summary}

The case here reported presents two congenital anomalies-congenital hypertrophy, and von Recklinghausen's disease. The left shoulder, left arm and hand, left leg and foot, are all larger than the right, but they are also definitely weaker. There is no evidence of syringomyelia, congenital hemiplegia, or pseudohypertrophy. Evidences of von Recklinghausen's disease are dorsal kyphoscoliosis, calcification of interspinous and anteri or common vertebral ligaments, cafe-au-lait pigmentation on the body, and a neurofibroma. The mental deficiency may be idiopathic or may be accentuated by, or due to, one or both of the congenital anomalies present.

\section{REFERENCES}

Gesell, A. (1921). Arch. Neurol. Psychiat., 6, 400.

Guillain, G., Alajouanine, Th., Huguenin, R. (1925). Rev. Neurol., 38, 778. 